\title{
Relato de experiência: somos livres ou predestinados? método e sequência didática de uma aula elaborada para uma turma do $9^{\circ}$ ano do ensino fundamental
}

\author{
Experience report: are we free or fated? \\ method and didactic sequence of a classroom prepared for a class of 9th year \\ of elementary education
}

\section{Andrei Luiz Lodea}

Professor na Universidade de Passo Fundo, Passo Fundo, Rio Grande do Sul, Brasil. lodea@upf.br

\section{Ângela Bárbara Rossetto}

Professora na Escola Estadual de Educação Básica Antônio João Zandoná, Barra Funda, Rio Grande do Sul, Brasil.

angelabarbararossetto@gmail.com

\section{Carina Tonieto}

Professora no Instituto de Educação, Ciência e Tecnologia do Rio Grande do Sul, Ibirubá, Rio Grande do Sul, Brasil.

carina.tonieto@upf.br

\section{Cínthia Roso Oliveira}

Professora na Universidade de Passo Fundo, Passo Fundo, Rio Grande do Sul, Brasil.

cinthiarsm@gmail.com

ORCID: https://orcid.org/0000-0002-8741-485X

Recebido em 02 de setembro de 2018

Aprovado em 11 de dezembro de 2018

Publicado em 23 de janeiro de 2019

RESUMO: Este artigo apresenta um relato de experiência realizada com uma turma do $9^{\circ}$ ano do Ensino Fundamental. A metodologia utilizada para realizar a intervenção partiu do pressuposto de que precisamos conhecer o universo cultural do aluno para a partir daí elaborar o planejamento, com vistas a desenvolver sua autonomia. Então, a partir de um questionário com aquele intuito, foi elaborado o plano de aula "Liberdade X Destino". Os passos didáticos foram uma mescla das sequências abordadas por Kohan (1999) baseado em Lipman (1995) e Trombetta (2002; 2013), os quais se seguem: sensibilização, problematização, investigação filosófica e sistematização. A partir da avaliação dos alunos sobre o que mais gostaram da aula, todos de certa forma se referiram ao debate, 
sendo que um especificou que ao exporem ideias diferentes das suas nos debates, eles puderam pensar para além da sua própria. Isso nos chamou muito a atenção e nos deixou muito satisfeitos, pois um dos principais objetivos de uma aula de filosofia é permitir ampliar os pontos de vista sobre os problemas, e foi isso que procuramos fazer, não criar um consenso, mas sim estimular que cada um conseguisse refletir sobre os diferentes pontos de vista.

Palavras-chave: Destino; Liberdade; Relato de Experiência.

ABSTRACT: This article presents a report of an experience carried out with a group of the final year of Elementary School in Brazil (9th grade). The methodology used to perform the intervention was based on the assumption that the cultural universe of the student must be acknowledged so that the planning can be elaborated accordingly, with a view to developing the students' autonomy. Hence, from a questionnaire with that intention, the class plan "Freedom vs. Destiny" was elaborated. The didactic steps were a combination of the sequences approached by Kohan (1999) based on Lipman (1995) and Trombetta (2002; 2013), which include: sensibilization, problematization, philosophical investigation and systematization. All students, to some extent, referred to the discussion as one of their favorite part of the class. One student specified that by putting into debate ideas that differ from their own enabled them to think beyond. This has attracted a great deal of attention, as one of the main objectives of a Philosophy class is to broaden our viewpoints on problems, which is what we intend to do, not to create a consensus, but rather to encourage each one to reflect on different points of view. Keywords: Destiny; Experience Report; Freedom.

\section{Introdução}

Uma universidade que pretende fornecer uma formação profissional, científica e política com o fim de beneficiar a sociedade, deve se sustentar em três eixos: o ensino, a pesquisa e a extensão. O curso de Filosofia da Universidade de Passo Fundo (UPF) visando atender à essa demanda mantém o projeto de extensão "Grupo de Estudos em Filosofia-GEF" vinculado ao Programa de Extensão Ensino e Inovação do Instituto de Filosofia e Ciências Humanas (IFCH). Este projeto tem como objetivo pensar aulas de Filosofia para turmas dos anos finais $\left(6^{\circ}, 7^{\circ}, 8^{\circ}\right.$ e $\left.9^{\circ}\right)$ do Ensino Fundamental e para os três anos do Ensino Médio e, posteriormente, realizar a intervenção. Essas atividades se alimentam também das pesquisas realizadas pelos professores tanto da universidade ${ }^{1}$ quanto da escola, bem como dos(as) acadêmicos(as) envolvidos(as) e que tem reflexo no processo ensino-aprendizagem. O que corrobora a interdependência das atividades de ensino, pesquisa e extensão que devem juntas formar o futuro profissional e aprimorar a formação dos que já estão atuando.

O relato que se segue é fruto do trabalho realizado no segundo semestre do ano de 2017. A escola laboratório vinculada ao projeto é a Escola de Educação Básica Antônio João Zandoná de Barra Funda-RS, escola estadual que heroicamente diante das crises econômicas e políticas se mantém firme no objetivo de fazer uma educação de qualidade, não com ênfase apenas no domínio do conteúdo, acesso à informação, ou competência reduzida à eficiência e eficácia profissional, mas na tentativa de diminuir as desigualdades e criar possibilidades de uma educação que gere o empoderamento do sujeito para ser um cidadão pensante e que ajude nas tomadas de decisões políticas. A proposta pedagógica da escola pautada na teoria crítica e na pedagogia freireana costuma partir das demandas da comunidade para planejar as suas aulas. Naquele momento, a fala surgida da pesquisa participante na comunidade que estava sendo problematizada na escola era "Eles que têm cabeça boa deveriam aproveitar para estudar; pegam uns troco e vão fazer festa." A partir daí, refletimos sobre o porquê 
isso ocorria. E em meio ao diálogo foi colocado que a metodologia para o ensino de filosofia baseada em Lipman, Sharp e Oscanyan (2001), Kohan (1999) e Trombetta (2002; 2013) era uma aposta que tínhamos para envolver os alunos, porque partimos do seu universo cultural para sensibilizá-los sobre um problema que seja importante para eles e a partir daí, investigamos e aprofundamos a reflexão sempre questionando e valorizando o que os alunos pensam.

Então, decidimos realizar um levantamento de dados com as turmas da escola participante do projeto investigando aspectos da vivência cultural ${ }^{2}$ dos alunos e alguns temas que eles gostariam de discutir. Feita a compilação dos dados, definimos uma turma de cada professor participante do projeto e dividimos os grupos de trabalho compostos em geral por um professor da escola, um professor da universidade ou mestrando(a) e um(a) acadêmico(a) da graduação em Filosofia. Ao fazer a análise dos temas mais votados, analisamos aqueles com maior potencial filosófico; em seguida definimos a turma, o respectivo tema geral e o grupo de trabalho que ficaria encarregado de planejar uma aula norteada por um problema filosófico em torno do tema e que levasse em consideração as vivências culturais dos alunos.

Esse relato é sobre a intervenção realizada no dia 22 de novembro de 2017 na turma do $9^{\circ}$ ano do Ensino Fundamental sobre o tema "Liberdade X Destino". O artigo está estruturado em três partes, inicialmente expomos a metodologia e a sequência didática escolhidas para a intervenção; em seguida, apresentamos o relato da experiência; por fim, fazemos uma autoavaliação da intervenção realizada.

\section{Metodologia e sequência didática}

A educação, como já dizia Kant (2011, p. 173), deve preparar "primeiro, o homem sensato, depois o homem racional e, por fim, o douto". Precisamos ensinar a filosofar, precisamos de um ensino que prepare para a vida, que prepare para o pensar de forma autônoma, antes de um ensino focado na história da filosofia (KANT, 2011, p. 174). Pois, do contrário, não há sentido algum em investir numa educação que prepara pessoas apenas para memorizar dados históricos. É esse intuito que fundamenta a perspectiva metodológica adotada para ensinar filosofia. Perspectiva que busca problematizar situações do cotidiano dos alunos para auxiliá-los a argumentar, a traçar consequências, a exemplificar, a perceber pressupostos, etc. de modo a desenvolver seu raciocínio lógico. Seguimos a perspectiva de Lipman, Sharp e Oscanyan (2001, p. 154-157), considerando que uma boa aula de filosofia é aquela em que parte sim, das opiniões dos alunos, mas que tem um progresso cumulativo seja na elaboração de um problema mais específico a ser investigado, no esclarecimento do próprio problema, no esclarecimento de algumas distinções ou na consideração e avaliação de possíveis respostas para um problema relacionado ao cotidiano dos alunos.

De acordo com Trombetta (2013, p. 10-11), o método refere-se à clareza sobre o ponto de partida e sobre o ponto de chegada. Para um professor ter clareza sobre seu método, ele precisa saber qual seu objetivo com a aula e como ele irá dar início ao processo. Esse ponto de partida para o início do processo pode ser um texto da tradição, um tema social 
atual, uma inquietação existencial, etc. A escolha desse ponto de partida e da forma como irá se desenrolar o processo da aula que é norteada pela finalidade que se quer alcançar, qualifica o método como: histórico, sociológico, da cultura geral ou reflexivo (TROMBETTA, 2002, p. 235-237). No método reflexivo, o ponto de partida é o universo cultural dos alunos e o ponto de chegada, é a autonomia dos mesmos ao experimentarem um problema filosófico e conseguirem pensar por si mesmos na busca por soluções (TROMBETTA, 2013, p. 11-15). Método este que está de acordo com o pressuposto kantiano a respeito da educação.

Para dar conta do método reflexivo, utilizamos uma sequência didática que é uma mistura das propostas de Trombetta (2002, p. 244-245) e Kohan (1999, p. 93-110) baseada em Lipman (1995, p. 349-351)3. Os seguintes passos são: sensibilização, problematização, investigação filosófica e sistematização. Esses passos não são necessariamente realizados de forma independente um do outro, mas se mesclam e surgem novamente ao longo do processo dependendo da necessidade.

A sensibilização é feita a partir do universo cultural dos alunos, pois é a partir daí que é possível fazer com que os alunos experimentem uma situação cotidiana, emocionem-se e se envolvam com ela para vivenciar o problema filosófico. Diferentemente da proposta de Lipman (1995) e Kohan (1999), pensada para o ensino de filosofia com crianças, na qual a problematização é feita pelas próprias crianças ao sugerir perguntas sobre o recurso da atividade prévia, na perspectiva adotada, segundo Trombetta (2002, p. 244), ela é planejada e feita pelo(a) professor(a) [mas não necessariamente] ao questionar a turma sobre um problema filosófico a partir do universo cultural deles. A investigação filosófica é o momento mais importante do processo, no qual se parte das opiniões dos alunos a respeito do problema proposto e a partir daí aprofunda-se a reflexão. Para isso, é possível relacionar as perspectivas dos alunos com algumas perspectivas teóricas já elaboradas pelos filósofos da tradição valorizando as falas dos alunos e explicando de modo geral a perspectiva do filósofo ao qual o ponto de vista do aluno se assemelha. A investigação é orientada de modo a buscar pressupostos das perspectivas dos alunos, identificar concordâncias e discordâncias entre eles bem como apontar falácias, traçar consequências dos pontos de vistas etc. (LIPMAN; SHARP; OSCANYAN, 2001, p. 143-176). A sistematização é um momento de refazer o processo desde o ponto de partida até o ponto de chegada, avaliando tanto 0 que foi aprendido quanto ao conteúdo quanto em relação às habilidades que haviam sido estabelecidas como objetivos de aprendizagem (TROMBETTA, 2002, p. 245; 2013, p. 14-15).

Com esses passos bem feitos, acreditamos que o objetivo maior de desenvolver a autonomia do indivíduo para pensar por si mesmo, ter bom-senso e saber viver em sociedade de forma crítica e reflexiva será alcançado. E com base nessa metodologia foi pensada a aula sobre "Liberdade X Destino" a partir de dois dos conceitos mais votados pela turma do $9^{\circ}$ ano da Escola Zandoná. 


\section{Relato da aula}

A aula teve início com a atividade de sensibilização prevista no plano. Questionamos os alunos se eles queriam se dividir em 3 grupos ou se queriam que nós os separássemos, eles escolheram se dividir por conta própria. Em seguida, cada grupo recebeu imagens distintas uns dos outros e foi pedido para que cada um dos grupos explicasse com seus próprios critérios quais das imagens representavam situações em que se é livre ou não, colocando-as no cartaz de maneira ilustrativa. Dessa forma, os alunos se mobilizaram para discutir o tema da liberdade e foi possível perceber as primeiras impressões dos estudantes. Foi interessante perceber que um dos grupos conseguiu identificar situações como "meio termo", ou seja, perceberam que é possível ser ao mesmo tempo "livres" e de certa forma "predestinados".

Imagem 1 - Cartazes feitos pelos grupos

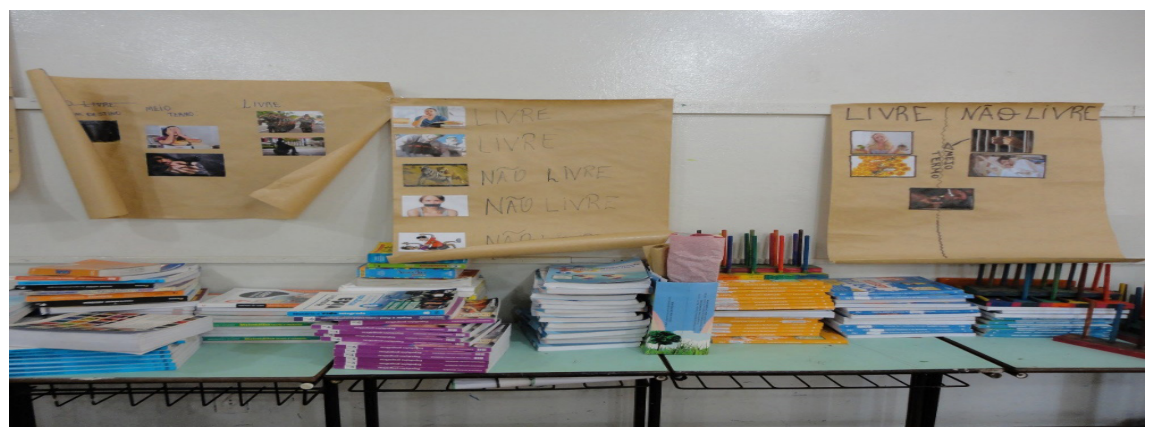

Fonte: própria

Começamos a problematizar algumas caracterizações feitas, por exemplo, da abelha fazendo mel que o grupo caracterizou como sendo livre, enquanto que a leoa atacando a zebra estaria seguindo seu destino guiada por sua natureza instintiva. Questionamos, no intuito de provocar a reflexão, se as abelhas seriam realmente livres ao fazer o mel ou estariam apenas seguindo as leis da natureza. A partir de alguns questionamentos como esse e das percepções dos colegas, o grupo mostrou-se flexível e revisou seu ponto de vista afirmando que as abelhas, ao contrário do que tinham dito, também estariam seguindo seu instinto.

Os alunos caracterizaram a imagem da mulher na cama de um hospital doente como não sendo livre, porque não escolhemos ter determinadas doenças. Então, os alunos chegaram a um consenso de que, neste caso, as pessoas também seguem as leis da natureza. Mas alguns alunos defenderam que apesar das características genéticas, podemos evitar algumas doenças dependendo da forma como agimos. Nesse momento foi colocado no quadro a definição de Platão de que ter liberdade é ter possibilidade de escolha (Rep., X, 617 e). E foi questionado: então podemos ser as duas coisas? Livres e predestinados ao mesmo tempo?

Problematizamos também a caracterização das mulheres afegãs usando burca como livres, questionamos se elas não seriam forçadas pela cultura a agir assim, perguntando: será que elas usam burca porque desejam ou porque a sociedade as impõe? A partir dessa problematização, os alunos afirmaram que as mulheres teriam liberdade de usar ou não, mas 
se não usassem teriam que arcar com as consequências. A aluna A disse que algumas podem querer usar burca. Nesse momento foi questionado se quando fazemos aquilo que queremos, somos livres. Com isso foi possível mostrar que ela pensava semelhante a Hobbes, pois ela definiu ser livre como poder fazer aquilo que se quer (ABBAGNANO, 2000, p. 608).

Então, problematizamos: as mulheres afegãs que desejam usar a burca, assim como os terroristas que sacrificam suas vidas em nome da religião, são realmente livres? Questionamos se a cultura em que nascemos não determina até mesmo o que desejamos. Os alunos concordaram e relacionamos isso com o pensamento de Baron d'Holbach, para o qual os seres humanos são determinados tanto pela natureza, quanto pelo contexto sociocultural a agir como agem. ${ }^{4}$ Mas alertamos que a ideia de Holbach parecia mais radical que a que alguns deles estavam defendendo. Pois, para o filósofo, o ser humano seria totalmente determinado por aqueles fatores, enquanto que alguns deles estavam defendendo que apesar do determinismo das leis da natureza ao qual estamos submetidos, ainda podemos escolher como agir.

A aluna $B$ afirmou que pensava que as pessoas são livres, mas algumas coisas da sua vida não podem ser mudadas. Outra, a aluna $C$, interrompeu e explicou que entendia que alguém é livre quando se tem vontade de fazer algo e o faz sem depender de ninguém. Nesse momento, mostramos que ela estava expressando um conceito de liberdade semelhante ao proposto por Aristóteles para o qual ser livre é ser autônomo, iniciando uma ação por si mesmo.

Voltando à fala da aluna $B$, questionamos se então tem algumas coisas da nossa vida que não podemos mudar. Se, por exemplo, quando acontecem acidentes, será que não estava no nosso destino passar por aquilo? Nesse momento, dissemos que íamos passar uma parte de um seriado que eles assistiam. ${ }^{5}$ Eles ficaram muito animados e descobriram que era o Sobrenatural, fazendo hipóteses e comentários sobre qual episódio seria proposto para o debate. Infelizmente, o datashow demorou um pouco a funcionar. Mas conseguimos passar as cenas em que Sam e Dean confrontam o escritor da história em quadrinhos que sabe tudo sobre suas vidas e que estava achando que era um Deus cruel que fazia eles passarem por todas as maldades e sofrimentos que passaram (MONSTRO, 2009).

Nesse momento, questionamos se nossas vidas não estão todas traçadas por um Deus. Alguns concordaram e outros não, então dissemos que quem concordava, pensava como os filósofos estóicos (Crisipo, Posidônio e Zenão) que acreditavam que a nossa vida é traçada por uma providência divina (DIÓG. L., VII, 149 apud ABBAGNANO, 2000, p. 243).

Nesse momento, a aluna $D$ disse que "ela não sabia nem mais quem ela era e que já tinha desistido da discussão..." o que mostra que o objetivo da aula de filosofia que é questionar o senso comum estava sendo atingido. Certamente o objetivo das aulas de filosofia não é provocar problemas existenciais, mas como repensar essas questões de forma crítica transforma o indivíduo, é inevitável que aconteça uma primeira desestabilização como essa. Entretanto, o interessante foi que essa aluna estava envolvida na discussão e depois desse comentário continuou participando. Ela fez esse comentário com brilho nos olhos e não com mera irritação.

$A$ aluna $B$, respondendo à pergunta apresentada após o vídeo, disse que acreditava que Deus tinha nos dado a vida, mas que era nossa escolha ir para o caminho da luz ou para o das trevas. Nesse momento, esclarecemos que ela pensava semelhante 
ao filósofo Peter van Inwagen para o qual somos livres, e Deus nos deu a liberdade que é um bem maior que qualquer maldade que possa acontecer (STERLING, 2013, p. 57). ${ }^{6}$ Mas, então, questionamos se Deus não seria mau por permitir que maldades como acidentes aconteçam nas nossas vidas. A aluna B defendeu que se a pessoa provoca um acidente ela seria a única responsável e não seria o destino. Porém, outros alunos afirmaram que, mesmo assim, poderia ser parte de seu destino provocar um acidente. Diante da fala da aluna $B$, questionamos se seria parte do destino existirem crianças passando fome na África e se isso faria de Deus um ser maldoso (BRUCE; BARBONE, 2013, p. 55). A aluna B replicou que Deus permite que essas coisas aconteçam para as pessoas aprenderem algumas lições para serem pessoas melhores.

A partir disso, e do tempo que estava se esgotando, dissemos que eles não precisam pensar todos da mesma forma, mas é importante que argumentem de forma coerente e que para investigarmos qual posição pode ser mais interessante de adotar poderíamos pensar quais as consequências de adotar uma ou outra posição. Então, questionamos os alunos quais os aspectos positivos de pensarmos que somos predestinados. Como já citado acima, o fato de recebermos lições de vida por Deus, ou de poder aceitar com mais facilidade a perda de entes queridos foi apresentado. Já os aspectos negativos seriam o fato de ser impossível responsabilizar as pessoas pelos seus atos, uma vez que as pessoas não teriam como agir diferente da que agiram pelo fato de o destino ser imutável (SÁNCHEZ VÁZQUEZ, 2008, p. 107-132).

Por outro lado, o aspecto bom de pensar que somos livres é que podemos mudar o que não gostamos na nossa vida, mas pelo mesmo motivo, as pessoas se sentem mais responsáveis pelos seus atos. Para exemplificar isso, apresentamos uma situação hipotética em que a aluna $\mathrm{D}$ agride a aluna $\mathrm{E}$ em virtude de um surto psicótico. E questionamos se ela seria completamente responsável pelo dano causado? Com isso, a aluna $\mathrm{D}$ e a turma pareceu concordar que, às vezes, é injusto pensar que temos toda a responsabilidade pelo que acontece.

Comojá era quase meio dia foi solicitado que cadaalunofizesse uma síntese escrita respondendo à questão: "É melhor pensar que somos livres ou predestinados?" e que justificasse a sua posição considerando o que foi discutido em aula. Além disso, foi solicitado que fizessem uma avaliação da aula especificando o que gostaram, o que não gostaram da aula e dessem sugestões. Foi possibilitado que entregassem na próxima aula com a professora participante do projeto.

\section{Autoavaliação da aula}

O que foi efetivamente trabalhado em aula estava previsto no plano. Apenas a atividade de síntese foi modificada um pouco, pois no plano inicial estava previsto que os alunos iriam ao final da aula refazer a mesma atividade inicial categorizando as imagens agora com os conceitos estudados e a reflexão feita. O objetivo também era avaliar se os alunos iriam mudar de posição ou não. Em virtude do adiantado da hora, não conseguimos encaminhar essa atividade, apenas a atividade escrita que também tínhamos previsto de realizar caso sobrasse tempo. 
O plano de discussão previsto, as principais questões foram colocadas, claro que a ordem modificou um pouco, pois problematizávamos as falas dos alunos de acordo com o que eles traziam e aproveitávamos para ir inserindo a ideia dos filósofos que já haviam pensado semelhante a eles. Essa é uma boa forma de permitir que os alunos tomem conhecimento da tradição sem ser meramente um ensino focado na história da filosofia. Essa metodologia provavelmente não envolveria tanto os alunos na reflexão do problema investigado pelo filósofo, que é o mais importante.

As atividades de sensibilização, as imagens e o recorte do vídeo da série Sobrenatural funcionaram muito bem para mobilizar os alunos para a discussão, porque foram imagens de situações conhecidas por eles e o vídeo foi escolhido justamente por ter sido citado como uma série assistida pela maioria da turma.

O esquema do quadro ficou bem organizado, embora tenha havido pequenos erros de grafia de duas palavras, "Istoicos" e "Zanão", que seriam "Estoicos" e "Zenão". Conforme imagem a seguir:

\section{Imagem 2 - Esquema do quadro}

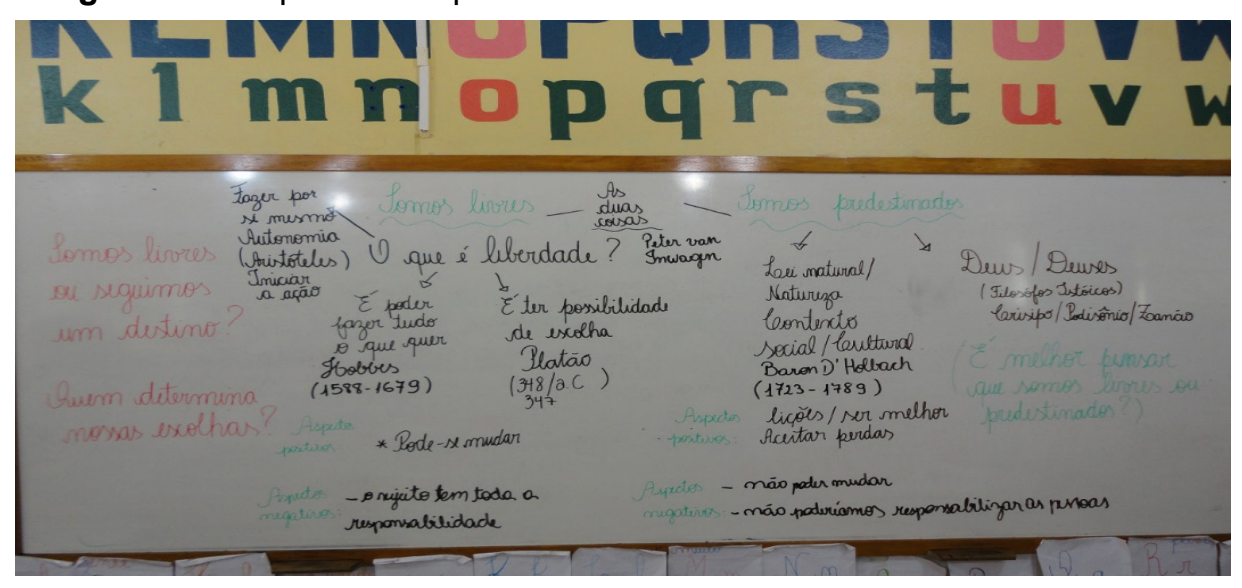

Fonte: própria

Tanto o esquema no quadro, quanto o plano de discussão foi um trabalho refeito várias vezes durante o planejamento e que a partir da realização da intervenção com o próprio grupo de estudos foi possível perceber o que poderia melhorar. Assim, foi imprescindível que a aula passasse pelo crivo dos(as) colegas professores tanto universitários e da educação básica, quanto dos(as) acadêmicos(as) do curso de filosofia e mestrandos(as) que participam do GEF. A experiência de todos contribuiu enormemente para que os planos fossem repensados e melhorados para a aplicação com a turma.

Um aspecto que foi negativo na intervenção, é que chegamos na sala e os alunos, que eram poucos (10 de 11 estavam presentes) estavam divididos em duas filas, a das meninas de frente para a dos meninos. E não tivemos a ideia de misturá-los, até porque tínhamos pensado em questioná-los se eles gostariam de se organizar ou de que fizéssemos a divisão dos grupos, para já começar a colocá-los na posição de escolher ou não sobre o que vai acontecer nas suas vidas. O fato deles terem escolhido se organizar, fez com que ficassem 6 meninos para um lado e 4 meninas para o outro. E apesar de os meninos estarem em maioria, as meninas participavam muito mais ativamente. 
Percebemos ao final da aula que a discussão acabou ficando mais concentrada em torno do que as meninas colocavam. E embora questionássemos os meninos, e algum em especial, para saber se discordavam do que alguma menina tinha afirmado, suas colocações não eram muito prolíficas. E nossa constatação foi confirmada com uma das avaliações dos alunos que ao responder à questão sobre o que menos gostou, escreveu: "A não participação parcial". ${ }^{7}$ A frase parece estar mal formulada, e fica mais claro quando confrontamos com a sugestão dada de "Mais atividades de interação de ideia". Então, quem escreveu essa avaliação percebeu que houve uma participação parcial da turma. Consideramos que isso realmente aconteceu, mas não foi um problema muito grande porque foi apenas uma avaliação nesse sentido das sete avaliações que retornaram.

Lipman, Sharp e Oscanyan (2001, p. 146) alertam para que numa discussão filosófica, é importante que o professor organize para que os estudantes não falem todos ao mesmo tempo nem fiquem sem falar. Na aula houve essa preocupação, mas faltou um pouco de habilidade para engajar mais os meninos na discussão e segurar um pouco a participação das meninas. Fizemos questões para os meninos na tentativa de não deixar o monopólio da discussão para o lado das meninas, mas não foi muito bem-sucedido. Por outro lado, é importante que os estudantes aprendam uns com os outros e não é porque alguns não participaram ativamente do debate que a aula não teve sucesso. Lipman, Sharp e Oscanyan (2001, p. 146-148) afirmam que é importante estimular que os estudantes aprendam uns com os outros e que, por vezes, estudantes que raramente falam estão acompanhando atentamente o debate que está sendo construído e podem também estar construindo uma série de ideias originais debatendo internamente consigo mesmos.

A aluna $B$ foi uma das que mais participou em uma parte da discussão afirmando que nossa vida pode ser predestinada por Deus, mas ao mesmo tempo somos livres. Problematizamos a sua posição e ao defender seu ponto de vista apresentando seus argumentos, alguns de seus colegas começaram a cochichar entre si e dar risadinhas que não percebemos de imediato. Ela interrompeu sua fala e questionou uma das colegas: "Fulana, tem algum problema?!". Essa foi uma situação constrangedora na sala e que antes que nós intervíssemos, a própria aluna se defendeu com uma pergunta não desrespeitosa, o que fez com que cessasse as risadas e os cochichos. Se o grupo tivesse mais encontros com a turma, teria que ficar atento se novos casos de preconceito religioso surgissem, para intervir de modo que os professores não ajam como se não estivesse acontecendo nada. É um valor muito importante o respeito mútuo entre os colegas, isso cria um ambiente de confiança em que todos se sentem acolhidos e confiantes em expressar suas crenças e argumentos para contribuir para a reflexão (LIPMAN; SHARP; OSCANYAN, 2001, p. 120-127).

Dos 10 alunos presentes, 7 entregaram a avaliação da aula e 8 entregaram a atividade de síntese solicitada ao final da aula. Sobre o que mais gostaram da aula, das 7 avaliações os estudantes apontaram: os cartazes (2), as atividades em geral (1), o bom entrosamento da turma (1), a curiosidade despertada (1), a possibilidade de expressar suas opiniões sem saber se estavam certas ou não (1) e todos de certa forma se referiram ao debate, sendo que uma delas especificou que ao exporem ideias diferentes das suas nos debates, "eles podem 
pensar não apenas na sua única ideia". Isso nos chamou muito a atenção e nos deixou muito satisfeitos, pois um dos principais objetivos de uma aula de filosofia é permitir ampliar os pontos de vista sobre os problemas, e foi isso que procuramos fazer, não criar um consenso, mas sim estimular que cada um conseguisse refletir sobre o seu ponto de vista e argumentar melhor para sustentar o já existente ou, até mesmo, mudá-lo diante de um argumento mais forte.

Um dos motivos talvez para que o debate tenha sido um dos aspectos que a turma mais gostou foi porque ficou evidente um progresso na discussão no sentido de dar possíveis respostas para o problema em questão. Diante da pergunta "Somos livres ou predestinados?", foi discutido pelo menos, quatro possibilidades: 1. Que somos livres (Aristóteles, Hobbes, Platão); 2. Que somos predestinados e seguimos um determinismo sociocultural e biológico (Holbach); 3. Que somos predestinados e seguimos um destino traçado pela providência divina (Estoicos); 4. Que somos livres, mas existe um Deus que nos criou (Peter van Inwagen).

Conseguimos construir algumas definições de Liberdade e traçar consequências de uma ou outra posição, exemplificando diferentes situações. Portanto, conseguimos desenvolver com a turma uma boa discussão filosófica, como defendem Lipman, Sharp e Oscanyan (2001, p. 154-157). É importante considerar que os fatores que mais contribuíram para o sucesso da discussão foi o bom planejamento da aula $\mathrm{e}$ preparação dos professores e alunos envolvidos na proposta da aula. Além da abertura para modificar o plano de aula inicial diante das sugestões dos colegas do grupo.

Os alunos apontaram como sugestões para a aula melhorar: mais tempo para realizar a atividade com as imagens no cartaz (2), mais dinâmica (1), mais atividade de interação de ideias (1) e um deixou em branco. Além disso, na reunião final de avaliação das intervenções a coordenadora do GEF, profa. Carina Tonieto, avaliou que foram bem produtivas as intervenções, mas uma sugestão para melhorar é que os alunos possam desenvolver ainda mais a escrita solicitando que inicialmente fosse feita uma reconstrução das possibilidades de responder à questão: "Somos livres ou predestinados?" a partir dos autores apresentados e do esquema feito no quadro e, num segundo momento, que apresentassem e justificassem o seu ponto de vista sobre o tema. Realmente, seria muito mais interessante que eles fizessem uma atividade mais completa como essa.

\section{Considerações finais}

Fazer com que os alunos, e nós próprios, tenhamos experiências filosóficas a cada encontro é uma arte e um ofício que exige muita dedicação. Apesar de não podermos controlar e saber com certeza se cada um experienciará o problema filosófico, existe uma forma de propiciar que isso se dê com maior probabilidade, que é primeiro, investigar o que os alunos gostariam de discutir, quais suas preferências culturais; e segundo, criar boas perguntas a partir de uma sensibilização que realmente esteja próxima da vivência cultural deles. Esse é "meio caminho" para que a experiência filosófica se dê. A partir daí, vem a arte de colocar as perguntas planejadas no momento certo (sabedoria esta que vem com a prática e com muito estudo), estando atento às falas dos alunos para ajudá-los a desenvolver o raciocínio lógico, de forma cuidadosa. 
Experiências do fazer filosófico tal como a que relatamos, são ótimas para ajudar os(as) estudantes a desenvolverem sua autonomia e os(as) professores(as) a continuarem aprendendo. É claro que uma intervenção como essa não faz sozinha tanta diferença, mas certamente ela faz com que se estabeleçam conexões neuronais que poderão ser reforçadas com novas atitudes investigativas e questionadoras vivenciadas em outros momentos e que levarão ao desenvolvimento de um bom-senso e de uma preparação eficaz para a vida!

\section{Referências}

ABBAgnANO, N. Dicionário de Filosofia. 4. ed. São Paulo: Cultrix, 2000.

BRUCE, M.; BARBONE, S. O problema do mal. In: BRUCE, M.; BARBONE, S. (Orgs.). Os 100 argumentos mais importantes da filosofia ocidental: uma introdução concisa sobre lógica, ética, metafísica, filosofia da religião, linguagem, epistemologia e muito mais. São Paulo: Cultrix, 2013. p. 54-55.

GALLO, S. A filosofia e seu ensino: conceito e transversalidade. In: SILVEIRA, R. J. T.; GOTO, R. Filosofia no Ensino Médio: temas, problemas e propostas. São Paulo: Edições Loyola, 2007. p. 15-36.

Ensino de filosofia, uma pedagogia do conceito: os quatro passos didáticos. In: GALLO, S. Metodologia do ensino de filosofia: uma didática para o ensino médio. Campinas: Papirus, 2012. p. 94-98.

HOLBACH, B. de. System of nature. [S. I.: s. n.], 1770. Disponível em: <http://www.dominiopublico.gov.br/download/texto/gu008909.pdf> . Acesso em: 14 set. 2015.

KANT, I. Notícia do Prof. Immanuel Kant sobre a organização de suas preleções no Semestre de Inverno de 1765-1766. In: . Lógica. Rio de Janeiro: Tempo brasileiro, 2011. p. 173-182.

KOHAN, W. O. Sugestões para implementar a filosofia com crianças em escolas.In: KOHAN, W. O.; WAKSMAN, V. (Orgs.). Filosofia para crianças na prática escolar. Petrópolis: Vozes, 1999. p. 85-112.

LIPMAN, M. O pensar na educação. Petrópolis: Vozes, 1995.

LIPMAN, M.; SHARP, A. M.; OSCANYAN, F. S. A filosofia na sala de aula. São Paulo: Nova Alexandria, 2001.

MONSTRO no final do livro. Sobrenatural. Direção: Mike Rohl. [S. I.]: Kripke Enterprises, Warner Bros. Television, Wonderland Sound and Vision. 2 abr. 2009.

PLATÃO. A república. 11. ed. Lisboa: Fundação Calouste Gulbenkian, 2008.

SÁNCHEZ VÁZQUEZ, A. Responsabilidade moral, determinismo e liberdade. In: Ética. 30. ed. Rio de Janeiro: Civilização Brasileira, 2008. p. 107-132. 
STERLING, G. A defesa do livre-arbítrio para o problema do mal. In: BRUCE, M.;

BARBONE, S. (Orgs.). Os 100 argumentos mais importantes da filosofia ocidental: uma introdução concisa sobre lógica, ética, metafísica, filosofia da religião, linguagem, epistemologia e muito mais. São Paulo: Cultrix, 2013. p. 56-58.

TROMBETTA, G. L. O papel da operação reflexiva no ensino e no exercício da filosofia: contribuições para uma ideia de filosofia no ensino médio. In: FÁVERO, A. A.; RAUBER, J. J.; KOHAN, W. O. (Orgs.). Um olhar sobre o ensino de filosofia. ljuí: Editora Unijuí, 2002. p. 235-247.

TROMBETTA, G. L. "Nos olhos": Método e didática no ensino de filosofia. In: TROMBETTA, G. L.; BORTOLINI, B. de O.; KAPCZYNSKI, A. L. Filosofia nos olhos: experiências de ensino. Passo Fundo: Berthier, 2013. p. 7-15.

\section{Notas}

1 Vários professores, acadêmicos e mestrandos participantes do projeto também são integrantes do Grupo de Estudos e Pesquisas sobre Educação Superior (GEPES/UPF) fundado e coordenado pelo Prof. Dr. Altair Alberto Fávero.

2 Como aspectos da vivência cultural, compreendemos suas crenças, desejos, hábitos de entretenimento, incluindo festas, pesquisas na internet, livros, jornais, desenhos, músicas, esportes e outros jogos, etc.

${ }^{3}$ Além desses autores, estudamos também a metodologia proposta por Sílvo Gallo (2007; 2012) a qual constitui-se dos seguintes passos: sensibilização, problematização, investigação e conceituação. A estrutura didática da aula foi pensada a partir das propostas desses autores que têm muito em comum.

${ }^{4}$ Essa ideia encontra-se no volume 1 do livro System of Nature publicado originalmente em 1770. A versão utilizada está disponibilizada no site <http://www.dominiopublico.gov.br/download/texto/gu008909.pdf>, acessado em 14 de setembro de 2015. A ideia citada está na página 105.

${ }^{5}$ O seriado foi escolhido com base no questionário sociocultural feito com os alunos antes das intervenções. Esse momento, na verdade, serve para sensibilizar novamente e problematizar. Mostrando que os passos não são estanques, mas se mesclam ao longo da aula.

${ }^{6}$ Ao ouvir a pronúncia do nome do filósofo, os alunos logo lembraram: "Ah, Van Gogh!". Foi um momento de descontração, a professora da escola esclareceu que este era o famoso pintor que cortou a orelha, mas que estávamos nos referindo a outra pessoa.

7 Foi a única resposta à essa pergunta, outros 2 estudantes disseram "nada", 1, "nada foi bem legal" e outro deixou em branco. Considerando que uma avaliação foi feita juntamente com a atividade de síntese e não foi colocado nada a respeito do que não se gostou.

\section{Correspondência}

Cínthia Roso Oliveira - Av. Brasil Leste, 285, São José, Universidade de Passo Fundo, Instituto de Filosofia e Ciências Humanas, CEP: 99.042-800, Passo Fundo, Rio Grande do Sul, Brasil.

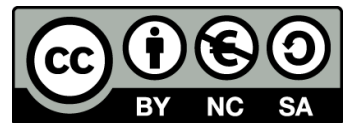

This work is licensed under a Creative Commons Attribution-NonCommercial 4.0 International (CC BY-NC 4.0) 